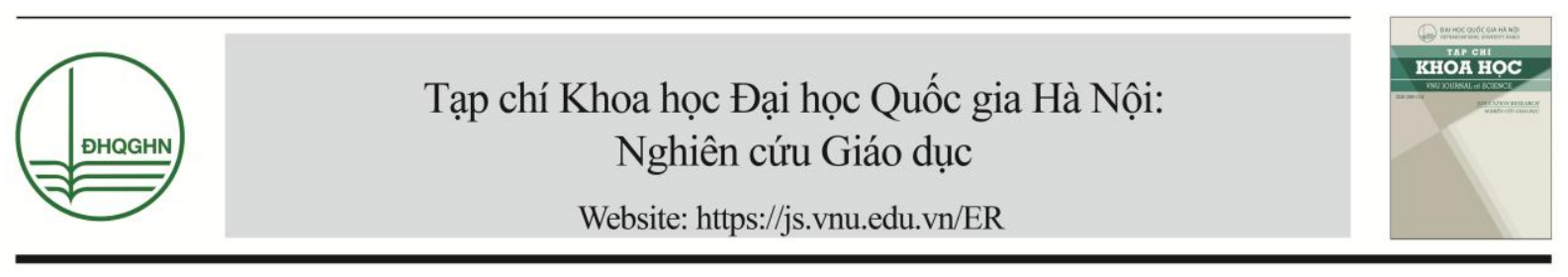

\title{
Khổng Tử dạy Kinh Thi và những bài học gợi ý cho dạy học Ngữ văn hiện nay
}

\author{
Dương Tuấn Anh", Trần Hoài Phương \\ Khoa Ngũ văn, Đại học Su phạm Hà Nội, 136 Xuân Thủy, Cầu Giấy, Hà Nội, Việt Nam \\ Nhận ngày 22 tháng 5 năm 2018 \\ Chỉnh sửa ngày 05 tháng 6 năm 2018; Chấp nhận đăng ngày 18 tháng 7 năm 2018
}

Tóm tắt: Kinh Thi là một trong năm bộ sách kinh điển của Nho giáo mà ở một số thời kì, thậm chí còn được coi là "sách giáo khoa" của toàn xã hội, được các học giả hết sức học tập và truyền tụng. Kinh Thi qua lời dạy của Khổng Tử được ghi rải rác ở nhiều thư tịch cổ; trong đó, có những lời dạy mang giá trị văn hóa, giáo dục, trở thành kinh điển. Bài viết này tập trung nghiên cứu một số lời dạy tiêu biểu, giúp gợi ý cho việc dạy học Ngữ văn trong nhà trường hiện nay. Trên cơ sở đó, bài viết muốn khẳng định lại lần nữa tính bền vững của những phương pháp mà Khổng Tử đề cập.

Tù khóa: Kinh Thi, Khổng Tử, dạy học Ngữ văn.

1. Kinh Thi (thời tiên Tần gọi là Thi) là một tập hợp thi ca, đã được người Trung Quốc sử dụng trong khoảng 2500 năm nay làm sách để dạy cho học trò. Khổng Tử (551 trước $\mathrm{CN}-479$ trước $\mathrm{CN}$ ) là người đầu tiên san định và dùng sách này dạy cho học trò. Sư kí của Tư Mã Thiên chép về việc Khổng Tử chỉnh lí lại Kinh Thi như sau: "Ngày xưa Thi có hơn ba ngàn thiên. Đến thời Khổng Tử, ông bớt những thiên trùng lặp, lấy những thiên có thể dạy lễ nghĩa, bắt đầu chọn từ Tiết (thủy tổ nhà Thương), Hậu Tắc (thủy tổ nhà $\mathrm{Chu}$ ), giữa thuật lại thời thịnh trị nhà Ân, $C h u$, cho đến thời lầm lỗi của $U$ Vương, Lệ Vương. Kinh Thi mở đầu từ mối quan hệ nam nữ, cho nên mới nói rằng: Khúc Quan thu mở đầu Phong, bài Lộc minh mở đầu Tiểu nhã, bài Văn vuoong mở đầu Đại nhã, bài Thanh miếu mở đầu Tụng.

\footnotetext{
* Tác giả liên hệ. ĐT.: 84-904239227.

Email: anhdt@hnue.edu.vn

https://doi.org/10.25073/2588-1159/vnuer.4140
}

Ba trăm lẻ năm thiên này đều được Khổng Tử gảy đàn và hát, để làm cho nó phù hợp với âm điệu Thiều, Vũ, Nhã, Tụng. Lễ nhạc từ đó mới khôi phục được diện mạo xưa để mà noi theo, nhờ đó làm cho vương đạo đầy đủ, lục nghệ trọn vẹn", [1].

Những ghi chép về việc dạy học và bàn luận của Khổng Tử về Kinh Thi được ghi lại rải rác trong nhiều thư tịch cổ như Lễ kí, Tả truyện, Sư kí... Riêng sách Luận ngũ đề cập tới vấn đề này nhiều nhất, 20 lần, trong các thiên $H o ̣ c n h i$, Vi chinh, Thái Bá, Tử Hãn, Tiên tiến, Tử Lộ, Vệ Linh Công, Quý thi và Duoong Hóa. Những ghi chép ấy cho thấy phần nào những quan điểm và

\footnotetext{
${ }^{1}$ Nguyên văn:

古者詩三千餘篇，及至孔子，去其重，取可施於禮義 上采契後稷 中述殷周之盛, 至幽庽之缺, 始於社席, 故曰, 關㫿之亂以為風始 鹿鳥為小雅台 文王為大雅台, 清朝為頌台。三百五篇孔子皆弦歌

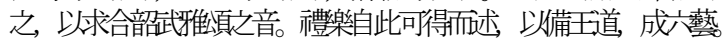
(Tư Mã Thiên - Sử kí, Trung Hoa Thư cục, 1959, trang 1936, 1937).
} 
phương pháp mà Khổng Tử đã dạy học cho các học trò của mình.

2. Những nghiên cứu về sách Luận ngũ đã được tiến hành hơn 2000 năm qua, từ các nghiên cứu về văn tự học, âm vận học, huấn hỗ học, thuyên thích học, triết học, văn học, giáo dục học, luân lí học, chính trị học... Tuy nhiên, những giá trị của cuốn sách này vẫn có thể được tiếp tục tìm tòi, phục vụ tốt hơn cho cuộc sống hôm nay.

Chính những ghi chép về việc dạy học và bàn luận của Khổng Tử về Kinh Thi sẽ là những bài học kinh nghiệm quý báu đối với người dạy học văn. Nhiều bài học trong số đó vẫn còn có giá trị đối với thực tiễn dạy học văn, phát huy những tinh hoa của nhân loại để góp phần vào sự nghiệp đổi mới giáo dục hiện nay.

3. Không ít lần Khổng Tử đưa ra lời nhận xét về Kinh Thi.

Thiên Quý thị sách Luận ngũ ghi lại lời đánh giá của Khổng Tử về Kinh Thi khi nói chuyện với con trai mình là Bá Ngư ${ }^{2}$ như sau: "Trần Cang hỏi Bá Ngur: Anh có nghe thầy dạy điều gì lạ không?. Bá Ngư đáp: Chưa thấy. Có lần cha tôi đứng một mình, Lí tôi rảo bước qua sân. Cha tôi hỏi: Học Thi chưa?. Tôi đáp: Con chưa học ạ. Cha tôi bảo: Không học Thi thì không biết lấy gì để nói. Lí tôi lui về học $T h i{ }^{4}$ [2]. Khi khẳng định "Không học Thi thì không biết lấy gì để nói”, Khổng Tử muốn nhấn mạnh giá trị của lượng ngôn từ và lượng tri thức phong phú cùng những phương thức diễn đạt uyển chuyển, tinh tế trong 305 bài của Kinh Thi.

Một lần khác, Khổng Tử lại nhắc con trai: "Con học Chu Nam, Thiệu Nam chưa vậy? Người không học Chu Nam, Thiệu Nam giống

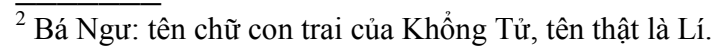

${ }^{3}$ Ý nói là có những điều dạy riêng, khác với nội dung dạy những học trò khác.

${ }^{4}$ Nguyên văn:

陳問於伯魚曰：「子亦有異聞乎?」對曰：「未也。嘗蜀立，鯉䞤 而過庭 曰：『學封乎?』對曰：『未也』『不學硅, 無以言。』 鯉退而學硅 (Trần Cang vấn u Bá Ngư viết: "Tử diệc hữu dị văn hồ?". Đối viết: "Vị dã. Thường độc lập. Lí xu nhi quá đình. Viết: "Học Thi hồ?". Đối viểt: "Vị dã". "Bất học Thi vô dĩ ngôn". Lí thoái nhi học Thi. ”)
}

như quay mặt vào tường mà đứng vậy chăng?"5 [2] (thiên Dương Hóa). Chu Nam, Thiệu Nam trong Kinh Thi dạy con người ta đạo lí tu thân tề gia. Chu Nam, Thiệu Nam cũng là những phong dao của vùng đất nhận được sự giáo hóa lê̂̉ nghĩa của thiên tử, nên vô cùng mẫu mực đáng học hỏi. Bởi vậy, học Chu Nam, Thiệu Nam sẽ học được lễ giáo làm người ấy, giúp con người ta có thể sải bước vững chắc trên con đường đời.

Về nội dung Kinh Thi, trong thiên Vi chính, Khổng Tử đánh giá: "Thi có ba trăm bài, một lời để khái quát về nó là: Suy nghĩ chính trực"6 [2]. Nội dung này cho phép Kinh Thi tiến hành thực hiện nhiệm vụ tu thân, khởi đầu cho sứ mệnh "tu thân, tề gia, trị quốc, bình thiên hạ" mà Nho giáo đặt ra cho mỗi cá nhân,

Thiên Kinh giải của sách Lễ ki cũng có lời đánh giá về đặc điểm của Kinh Thi như sau: "Con người ta làm người muốn được ấm êm đôn hậu, dùng Thi để giáo hóa vậy"7 [2], ý nói Kinh Thi giàu chất nhân văn, có thể gạn đục khơi trong tâm hồn, nên có thể dùng làm phương tiện để giáo hóa.

Dùng tác phẩm văn học làm thành những nguyên mẫu để người học tự điều chỉnh bản thân, phần Tiểu nhã , Khổng Tử dùng lời trong bài Ngã hành kì dã để giảng bài: "Tử Trương hỏi về việc đề cao đạo đức, phân rõ đúng sai. Khổng Tử nói: Chú trọng vào điều trung tín, noi theo chính nghĩa, chính là đề cao đạo đức vậy. Yêu mến người là muốn cho người được sống, ghét người là muốn người phải chết. Muốn người ta sống lại muốn người ta chết, ấy chính là còn nghi hoặc (không phân rõ được đúng sai)

\footnotetext{
${ }^{5}$ Nguyên văn:

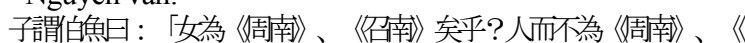
召南〉, 其猶正嘖面而立她與?」(Tử vị Bá Ngư viết: Nhữ vi "Chu Nam", "Thiệu Nam" hĩ hồ? Nhân nhi bất vi "Chu Nam" "Thiệu Nam" kỳ do chính tường diện nhi lập dã dư?)

${ }^{6}$ Nguyên văn:

子曰：詩三百，一訌蔽之，曰『思無邪』。」(Thi tam bách， nhất ngôn dĩ tế chi, viết: Tư vô tà.). Thực tế, Kinh Thi có hơn 300 bài, nhưng ở đây văn bản chỉ diễn đạt một con số tương đối.

${ }^{7}$ Nguyên văn: 其爲人也溫檸敦厚, 詩教也。 (Kì vi nhân dã ôn ninh đôn hậu, thi giáo dã.) - Lễ kí hiệu chú, Nhạc Lộc xuất bản xã (《礼记校主》岳麓柿戈), năm 2004, trang 385.
} 
vậy. (Thi có câu:) Thực chẳng bởi giàu có, cũng chỉ bởi đổi khác mà thôi”. (thiên Nhan Uyên) 8 [2]. Nguyên văn câu trích dẫn lấy từ bài $N g \tilde{a}$ hành kì dãa, là lời của người phụ nữ lấy chống xa bị phụ bạc. Trên đường rời bỏ nhà chồng trở về, người phụ nữ ấy có lời oán thán người chống bội bạc, khi xưa có tình cảm, giờ lấy người phụ nữ khác, chẳng bởi người kia giàu có hơn mà bởi người chồng thay lòng đổi dạ. Chẳng thế mà khi có người cư xử không đúng, Khổng Tử cũng đã có ý kiến phát biểu. Thiên Bát dật có đoạn chép: Ba quan đại phu lấy bài Ung để xướng lên khi kết thúc lễ tế tổ tiên mình. Đức Khổng tử nói: (Câu thơ) Vua chu hầu trơ tế, Thiên tử thể hiện sư tôn nghiêm" sao có thể được xướng lên ở miếu đương của ba quan đại $p h u^{9}$ [2]. Theo quy định xưa, khi có lễ tế ở tông miếu, thiên tử nhà Chu làm làm chủ tế, có vua chư hầu làm trợ tế. Sau khi tế xong, mọi người hát bài Ung (một bài thuộc $C h u$ Tụng của Kinh Thi) để kết thúc buổi tế. Đây là nghi thức dành riêng cho thiên tử nhà Chu, không ai được phép làm tương tự. Vậy mà ba quyền thần nước Lỗ là họ Mạnh Tôn, họ Thúc Tôn và họ Quý Tôn lại tiểm lễ். Những lời được Khổng Tử trích dẫn trong bài Ung tự nó đã nói lên bài này được ba quyền thần sử dụng không đúng bối cảnh, đương nhiên trái với lễ.

Những điều đã nêu ở trên cho thấy Kinh Thi không đơn thuần là thơ ca mà ở đó còn có những vấn đề học đạo; cơ hồ là sự khẳng định cho chức năng thẩm mĩ và cảm hóa của văn học - một luận điểm rất quan trọng cần được nhận thức rõ ràng trong khi dạy học Ngữ văn. Từng có ý kiến cho rằng "nếu xem chức năng của một sư vật nào đó nhu là xem xét lí do tồn tại của nó thì việc thỏa mãn nhu cầu thẩm mĩ cho con

\footnotetext{
${ }^{8}$ Nguyên văn:

子张照崇德 辩惑 子曰：「主忠信, 徙義 崇德也。愛之欲其生,

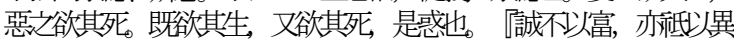
○』」(Tử Trương vấn sùng đức biện hoặc. Tử viết: Chủ trung tín, tỉ nghĩa, sùng đắc dã. Ái chi dục kỳ sinh, ố chi dục kỳ tử, ký dục kỳ sinh, hựu dục kỳ tử, thị hoặc dã. "Thành bất dĩ phú, diệc chi dĩ dị”).

${ }^{9}$ Nguyên văn:

三家者以雍㬚 子曰：「相睢辟公，天了穆敫，觅取於二家之堂

?」 (Tam gia giả dĩ Ung triệt. Tử viết: "'Tướng duy tích công; thiên tử mục mục!' Hề thủ ư tam gia chi đường?"
}

người là li do trục tiếp nhất của sụ tồn tại văn hoc ${ }^{10}$. Văn học đem đến cho người đọc những xúc cảm thẩm mĩ gắn liền với cái đẹp mà ở đó, cái đẹp không đơn thuần chỉ là cái đẹp hiện hữu bề ngoài. Nó còn có thể là cái bi, cái hài, cái cao cả, cái thấp hèn... - những biểu hiện khác nhau của đời sống phức tạp và đa tầng vốn luôn tồn tại. Văn học vì thế giúp bồi dưỡng nhận thức, tình cảm, hướng đển sự thanh lọc trong tâm hồn người đọc. Bên cạnh đó, "văn học không ngừng thỏa mãn nhu cầu thường thức cái đẹp của con người mà còn phát triển ở ho khả năng hành động, sáng tao theo quy luật ấy. Khi nói rằng nghẹ thuật làm phong phú đời sống con người, cũng có nghĩa là nó giúp con người nhay cảm hơn, tinh tế hơn trong hành động và cảm thu thế giới" ${ }^{\prime 1}$. Hiểu được chức năng thẩm mĩ, cảm hóa này, giáo viên mới đi sâu vào cái bản chất nhất của văn học để dạy Ngữ văn như dạy một nghệ thuật và dạy Ngữ văn như dạy một công cụ bồi đắp tâm hồn của học sinh. Từ đó, hoạt động dạy học trong nhà trường phủ nhận hai thực tế: Thứ nhất là không dạy học thuyết giảng một chiều, đem điều giáo viên nghĩ/cảm về tác phẩm hay nhân vật để áp vào học sinh và ép buộc học sinh cũng phải nghĩ/ cảm như vậy. Dạy học Ngữ văn nên là phương cách thuần khiết nhất giúp khơi gợi những tình cảm sáng trong, sự đồng cảm của bạn đọc với số phận con người. Thư hai, dạy học Ngữ văn không nên và không thể là một hình thức "đếm ý", cho rằng tác phẩm nhất thiết phải có chừng đó con số các ý thì mới là "đủ ỷ". Trong thực tế, mỗi bạn đọc với lăng kính tâm hồn khác nhau sẽ có những phản xạ khác nhau. Nếu không phủ nhận hai thực tế kể trên, vô tình chúng ta đã và đang triệt tiêu đi những xúc cảm tươi mới ở người học, biến các em thành chiếc máy học thuộc được lập trình sẵn và cài đặt cùng một kiểu định dạng cho môn học mà lẽ ra nên gắn với những xúc cảm tự thân nhất.

Thế nên, ngay cách Khổng Tử đề cập đến Kinh Thi cũng ít nhiều cho thấy sự uyển chuyển

\footnotetext{
$\overline{10}$ Bài viết "Tìm hiểu về tính thẩm mĩ trong văn học", kenhvanhoc.edu.vn

11 Bài viết "Tìm hiểu về tính thẩm mĩ trong văn học", kenhvanhoc.edu.vn
} 
trong tiếp cận và định hướng người nghe về giá trị của nó.

4. Có thể dễ dàng nhận thấy Khổng Tử đánh giá rất cao giá trị của Kinh Thi. Trong sách Luận ngũu, Khổng Tử nhiều lần, khi trực tiếp, khi gián tiếp cùng học trò đàm đạo về Kinh Thi. Những ghi chép này đã cho thấy một số phương pháp dạy học văn rất thú vị của vị sư biểu từ hơn 2500 năm trước.

4.1. Dạy Kinh Thi, Khổng Tử chủ trương phải hiểu sâu, hiểu kĩ, từ đó có thể vận dụng vào cuộc sống, không đề cao số lượng. Thiên Tử Lộ sách Luận ngũ đã ghi lại lời của ông khẳng định quan điểm này: "Đọc ba trăm thiên Kinh Thi, giao cho việc chính sự mà làm không nên; sai đi sứ bốn phương mà không biết tự mình ứng đối, như vậy dẫu đọc nhiều cũng để làm gì?" "12 [2].

Quan điểm của Khổng Tử giúp đưa đến những liên hệ thú vị về phương pháp dạy học hiện đại khi các nhà giáo dục chủ trương việc học gắn với hành, lí thuyết đi đôi với thực tiễn và phải soi mình vào thực tiễn để kiểm nghiệm tính đúng đắn. Trong thời đại bùng nổ thông tin và cuộc cách mạng 4.0 sôi động, lượng tri thức được sản sinh ngày một nhiều theo cấp số nhân. Hệ quả là kho tàng tri thức của nhân loại ngày càng được mở rộng; đi cùng với nó là những nguy cơ trong việc kiểm định tính đúng - sai. Học ít mà sâu và kĩ được đề cao ở chỗ đó. Nó giúp giảm thiểu những rủi ro trong tiếp nhận thông tin cũng như tăng cường tính thực tiễn của tri thức. Đi vào nhà trường, đã qua rồi thời kì phải trang bị cho học sinh tầng tầng lớp lớp các tác phẩm đồ sộ, kinh điển, yêu cầu học sinh phải biết rộng biết nhiều những điều kinh viện. Dạy học hiện nay nhấn mạnh vào tính cụ thể và chủ đề. Đó là giúp học sinh học lấy cái "cơ chế”, cái cốt lõi trong một thời đại, trong một trào lưu văn học hay trong quan niệm của một tác gia. Từ sự hiểu kĩ càng về cơ chế ấy, học sinh có thể vận dụng vào tự đọc, tự học những

\footnotetext{
12 Nguyên văn trong thiên Tủ Lộ: 詳寺三百, 授之以政, 不達; 使於四方, 不能專對; 雖多, 亦奚以為 ?(Tung thi tam bách, thụ chi dĩ chính, bất đạt; sử ư tứ phương, bất năng chuyên đối. Tuy đa, diệc hề dĩ vi?)
}

tác phẩm khác. Như thế, học sinh đã được học "cái tinh" để thấu hiểu "cái đa dạng".

Định hướng dạy học theo chủ đề này vì thế cũng gắn bó chặt chẽ với quan điểm dạy học theo định hướng phát triển năng lực; tức là chú ý vào sự "kết hợp các thuộc tính (kiến thức, kĩ năng, thái độ) cho phép một cá nhân/ nhóm người thưc hiện môt vai trò/ nhiệm vu đạt tới một chuẩn mưc/ chất luợng phù hợp trong hoàn cảnh cu thể" (Preston \& Walker, 1993), vào "khả năng vận dụng nhũ̃ng kiến thức, kinh nghiệm, kỹ năng, thái độ và hứng thú để hành động một cách phù hợp và có hiệu quả trong các tình huống đa dạng của cuộc sống" (Québec- Ministere de l'Education, 2004). Nói cách khác, điều học sinh thu nhận được không phải chỉ là những tri thức từ hoạt động đọc hiểu mà còn là cách vận dụng điều đã học vào thực tiễn và xét về lâu dài là tự học suốt đời.

4.2. Khổng Tử cũng dùng hình tượng để giảng giải. Chẳng hạn, thiên Thuật nhi có lời dạy của Khổng Tử: "Không uất ức vì không hiểu được thì ta không gợi mở cho; không bực tức vì chưa thông suốt thì ta chẳng hướng dẫn cho. Đã được ta dạy cho môt góc mà chẳng biết đem ba góc còn lại để đối chiếu thì ta chẳng dạy lại cho nữa" ${ }^{\prime 3}$ [2]. Mô tả kiến thức giống như các góc của một chiếc bàn, Khổng Tử muốn khẳng định rằng các phần kiến thức đều có thể liên hệ, lí giải cho nhau, nhất là những phần kiến thức tương tự nhau. Cách diễn đạt bảng hình ảnh này rất mộc mạc, đơn giản, nhưng cũng rất hiệu quả, dễ hiểu.

Văn học là nghệ thuật của ngôn từ, của xúc cảm, của hình tượng. Nhà văn xây dựng hình tượng như là một cách truyền tải ý niệm, quan điểm, suy nghĩ, trăn trở về cuộc đời và con người. Luận điểm trên của Khổng Tử giúp liên hệ tới một bài toán khác đối với dạy học Ngữ vắn hiện nay và nguyên tắc, phương pháp sư phạm của người giáo viên Ngữ văn. Đó là đảm bảo tính trực quan, dùng ngôn từ để giải thích cho khái niệm, dùng lời để hiện thực hóa một

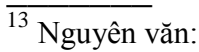

不憤不啟, 不棑不發, 舉一隅不以二隅反, 則不復也。(Bất phẫn bất khải, bất phỉ bất phát. Cử nhất ngung bất dĩ tam ngung phản, tắc bất phục dã.)
} 
hình tượng trừu tượng. Nói cách khác, vấn đề được quan tâm là làm sao để có thể sử dụng ẩn dụ như một phương pháp dạy học hiệu quả.

Ngữ văn trong nhà trường hiện đại được xem xét là một môn học công cụ, đồng thời là một môn học nghệ thuật. Điều đó dẫn tới hệ quả là mục đích của việc dạy học đã có sự thay đổi bản chất so với các giai đoạn trước. Người dạy cần thiết phải hướng dẫn để phát triển song song cả kĩ năng ngôn ngữ (linguistic skills) và năng lực giao tiếp nghệ thuật (communicative competence) cho người học. Tuy vậy, nói/ viết đúng đã khó; nói/ viết một cách nghệ thuật càng khó hơn. Cái đích cuối cùng là hướng dẫn để học sinh trong khi giao tiếp vừa thể hiện được ý đồ và mục đích, vừa mĩ hóa được hình thức của ý đồ, mục đích ấy một cách phù hợp. Theo cách tiếp cận như thế, ẩn dụ là một biểu hiện của việc sử dụng lời nói nghệ thuật trong giao tiếp, đồng thời tự thân nó cũng là một cơ chế có thể tường minh thành thao tác triển khai.

Xét trên bình diện ngôn ngữ học, tạo ra ẩn dụ là một cơ chế đặc biệt đòi hỏi một người phải nhận ra sợi dây kết nối giữa hai sự vật, hiện tượng tưởng như không có mối quan hệ đặc biệt gì với nhau. Vì thế, xét trên bình diện dạy học Ngữ văn (mà cụ thể là dạy học Tiếng Việt), nhiệm vụ của người giáo viên là giúp học sinh tường minh hóa cơ chế đặc biệt này và cách vận dụng chúng vào giao tiếp. Trong cuốn Tu tì hoc (The Philosophy of Rhetoric), I. Richards cho rằng cấu trúc ẩn dụ gồm có hai phần: $y$ nghĩa và phương tiện biểu lộ. Ở đó, ý nghĩa là cái bên trong, là những nội dung còn ẩn chứa sâu xa ở chủ thể vật; phương tiện là cái bên ngoài, là vỏ hình thức được sử dụng để truyền tải ý nghĩa. Việc lĩnh hội và sản sinh một ẩn dụ góp phần khiến lời nói hàng ngày trở nên nghệ thuật hơn; đồng thời khám phá sâu về khả năng sáng tạo, sử dụng ngôn ngữ vô biên của con người. Các tác giả cuốn sách "Các phương pháp dạy học hiệu quả" (Classroom Instruction that works) quan niệm ẩn dụ có thể được mô hình hóa để trực quan hơn. "Điểm quan trọng của mô hình này là nó cho biết môt sư thật rằng hai yếu tố có thể có nghĩa đen hoi khác nhau nhưng lại có chung một khuôn mẫu trùu tượg. Dùng mô hình, học sinh có thể điền vào các yểu tố của một ẩn dụ, nghĩa đen của mối yếu tố và nghĩa bóng liên hệ chúng tới nhau" "14 [3]. Mô hình này được thể hiện như sau:

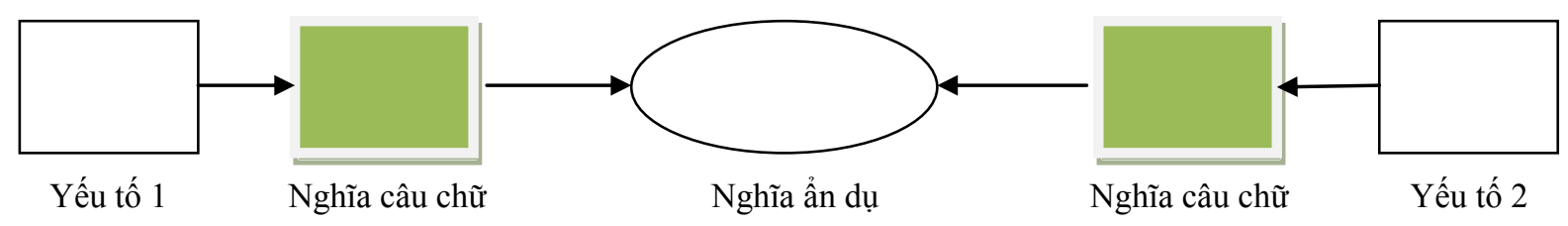

Úng chiếu vào cách mà Khổng Tử muốn truyền tải, hình tượng chiếc bàn bốn góc chẳng phải là cái "nghĩa bóng" của yếu tố 1 (kiến thức) mà học trò cần giải mã hay sao? Giải được mã này, chẳng những người học hiểu sâu xa hơn cái ý niệm mà thậm chí còn ghi nhớ lâu dài hơn những điều được ví von. Vì thế, thiết nghĩ ở thời đại nào, ở không gian giáo dục nào, việc giúp học sinh học, hiểu và vận dụng được cơ chế ẩn dụ cũng là một cách để mĩ hóa lời nói, tăng cường khả năng liên tưởng và tư duy sáng tạo.

\footnotetext{
${ }^{14}$ Nguyễn Hồng Vân dịch (2011), Các phuoong pháp dạy học hiệu quả, NXB GDVN, trang 35.
}

4.3. Khổng Tử cũng chú trọng liên hệ thi ca với thực tế đời sống. Ống cho rằng, người học Kinh Thi nghiêm túc có thể trở thành người tốt, biết tu dưỡng bản thân. Thiên Tiên tiến kể rằng: "Nam Dung đọc đi đọc lại lời thơ "bạch khuê", Khổng Tử bèn đem con của anh mình gả cho" "15 [2]. Lời thơ "bạch khuê" chính là lời của bài UÚc trong phần Đại Nhã của Kinh Thi, trong đó có đoạn: "Bạch khuê chi điếm, thượng khả ma dã, tư ngôn chi điếm, bất khả vi dã" (Ngọc trắng có

\footnotetext{
$\overline{15}$ Nguyên văn: 南容三復白圭, 孔子以其兄之子妻之。(Nam Dung tam phục Bạch Khuê, Khổng Tử dĩ kỳ huynh chi tử thế chi).
} 
vết còn có thể mài hết đi được; lời nói mắc lỗi thì không cứu vãn được.)

Tử Cống hỏi "Nghèo mà không nịnh bợ, giàu mà không kiêu ngạo, (người như vậy) như thế nào?". Khổng Tử đáp "Khá đấy, nhưng chưa bằng nghèo mà lạc đạo, giàu mà chuộng 1ễ”. Tử Cống nói: “Thi rằng: "(Phẩm hạnh của nhà vua được tu dưỡng) như cắt như chà, như giũa như mài (giống như một món đồ quý báu được chế tác cẩn thận, tỉ mỉ)", là nói về loại người này chăng?". Khổng Tử nói “Trò Tứ này, có thể bắt đầu cùng bàn luận Thi được rồi. (Trò là người) nói cho biết về những điều đã học thì đã hiểu điều sẽ học"16 [2]. Câu thơ Tử Cống đề cập đến nằm trong bài Kì úc (Khúc cong sông Kì), ca ngợi phẩm hạnh, đạo đức của Vệ Vũ Công (khoảng 853 tr. $\mathrm{CN}-758$ tr. CN).

5. Việc Kinh Thi được sử dụng với tư cách một cuốn sách dạy cho học trò trong suốt 2500 năm tự thân đã là lời khẳng định cho những giá trị văn hóa lâu bền, có tính ổn định cao đến mức trở thành quy luật, chân lí. Tuy vậy, muốn những giá trị văn hóa ấy có sức sống thì bao giờ cũng cần sự vận dụng, cần những người thầy để khai phá nội hàm sâu xa của chúng vào thực tiễn. Trường hợp Khổng Tử dạy Kinh Thi, theo chúng tôi, là một điển hình như thế. Cách tiếp cận khoa học, chú trọng vào cái tinh hoa, cốt lõii, bản chất giúp người đọc hiểu Kinh Thi không đơn thuần chỉ là một tập hợp thơ ca mà hơn thế, còn là những bài học trân quý về đạo học, đạo làm người. Đồng thời, cách tiếp cận ấy còn giúp gợi dẫn đến việc giảng dạy Ngữ văn ở nhà trường hiện đại.

Nghiên cứu từ những lời giảng cổ và ngẫm đến những phương pháp dạy học mới giúp khẳng định: có những quan điểm không bao giờ lỗi thời bất kể thay đổi của thời gian. Ở đó, dù trong thời đại nào, bối cảnh xã hội nào, dù được diễn đạt dưới hình thức ngôn ngữ nào thì xét đến cùng, cái nội hàm tư tưởng sâu xa là hướng về người học và lấy hoạt động học của học sinh làm trung tâm vẫn luôn là cái đích cuối của quá trình đào tạo. Chỉ khi thực hiện được điều đó, dạy học trong nhà trường nói chung, dạy học Ngữ văn nói riêng mới hoàn thành được nhiệm vụ cao cả của mình.

\section{Tài liệu tham khảo}

[1] Tư Mã Thiên: Sủ kí, Trung Hoa thư cục, 1959 ( 司馬遷: 史記, 中華書局, 1959).

[2] Trương Yến Anh chú thích (2006): Luận ngũu, Trung Hoa thư cục (张燕婴 译注: 论语中华经典藏书, 中华书局, 2006).

[3] Nguyễn Hồng Vân dịch (2011), Các phương pháp dạy học hiệu quả, NXB Giáo dục Việt Nam.

\title{
Confucius Teaching the Classic of Poetry and Recommend Ideas for Modern Philology Teaching
}

\author{
Duong Tuan Anh, Tran Hoai Phuong \\ Faculty of Philology, Ha Noi National University of Education, \\ 136 Xuan Thuy, Cau Giay, Hanoi, Vietnam
}

\footnotetext{
Abstract: The Classic of Poetry is one of the five classic books of Confucianism which was even considered "a textbook" of the whole society, learned and popularized by scholars at some times. The

$\overline{16}$ Nguyên văn:

子貢曰：「貧而無諂，富而無驕，何如？」子曰：「可也。未若貧而樂，富而好禮者也。」子貢曰：「《詩》云：

『如切如磋，如㻟如磨。』其斯之謂與？」子曰：「賜也，始可與言詩已矣！告諸往而知來者。」(Tử Cống viết: "Bần nhi vô siểm, phú nhi vô kiêu, hà như?" Tử viết: "Khả dã. Vị nhược bần nhi lạc, phú nhi hiếu lễ giả dã." Tử Cống viết: "Thi vân: "Như thiết như tha! như trác như ma", kì tư chi vị dư?" Tử viết: "Tứ dã! Thủy khả dữ ngôn Thi dĩ hĩ! Cáo chư vãng nhi tri lai giả").
} 
Classic of Poetry through the teachings of Confucius was scatteringly written in many ancient books in which, there were lots of teachings of great cultural and educational value becoming classics. This article focuses on some of the typical teachings that guide the teaching of Literature in Vietnam highschools. Basically, it reaffirms the sustainability of the methods that Confucius mentioned before.

Keywords: The classic of poetry, Confucius, teaching literature. 